\title{
Use of a New Transportation Algorithm for Profit Maximization
}

\author{
Arifuzzaman, \\ Department of Mathematics, Faculty of Science, \\ Fareast International University (FIU), Bangladesh \\ Md. Salehin Ferdous Kader, \\ Homayra Alam, \\ Department of Electrical and Electronic Engineering (EEE), \\ Faculty of Engineering, Fareast International University (FIU), Bangladesh
}

Doi: 10.19044/esj.2019.v15n15p262 URL:http://dx.doi.org/10.19044/esj.2019.v15n15p262

\begin{abstract}
A transportation calculation is advanced, and it makes it possible to be able to effectively plan the assets with the end goal of augmenting the benefit of an assembling organization. The distribution indicators (DI) have been resolved from the distinction of the bigger unit profit and the average value of total unit profit of each row and column. Also, the area of the fundamental cells has been resolved as the biggest entrance of the transportation table (TT) along the biggest DI. The most extreme benefit given by this calculation is closer to the other benefit. The strategy, however, is represented with numerical examples to legitimize its proficiency.
\end{abstract}

Keywords: DI, TT, Unit profit, Average of total unit profit

\section{Introduction}

Transportation performs a very essential role of guaranteeing the proficiency, development, and easy accessibility of verdant materials and completed merchandise from sources to destinations while fulfilling, as far as possible, the request prerequisite. Therefore, this results to a low cost of transportation. There is an effect of transportation cost on benefit maximization. The subsist transportation calculations such as Vogel's Approximation Method (VAM), North West Corner (NWC) Method, and Matrix Minima Method have been utilized with the end goal to take care of transportation issue for a long time (Gupta \& Hira, 2009; Kapoor, 2002). Presently, numerous analysts are growing new strategies for tackling transportation issues. This includes korukoglu enhanced Vogel's Approximation Method (IVAM) for the Transportation problem (Korukoglu, 
\& Balli, 2011), Kasana Extreme Difference Method (EDM) for the Transportation problem (Kasana \& Kumar, 2004), and Balakrishnan's Modified Vogel's Approximation Method for Unbalance Transportation problem (Balakrishnan, 1990). However, we may solve the maximization transportation problem by any of the techniques just referenced. Here, we present another transportation calculation that can effectively solve any type of interest maximization problem.

Also, we expect that the reciter is very much familiar with transportation issue and asset distribution for benefit maximization. Thus, we would exhibit our created calculation.

\section{Algorithm of the New Method}

Step 1: $\quad$ Put the row and the column allocation markers just after and underneath the supply limits and request necessities respectively inside first brackets. These are the distinction among the bigger unit benefit and average values of complete unit benefit of each row and column of TT.

Step 2: $\quad$ Recognize the most elevated allocation pointer and pick the best unit benefit along to most elevated DI. In the event that there are at least two most noteworthy pointers, pick the most elevated marker along with the best unit benefit which is available.

Step 3: $\quad$ Allocate $x_{i j}=\min \left(a_{j}, b_{j}\right)$ on the left-apex of the best unit benefit in the $(i, j)$ th cell of the TT where $x_{i j}$ is the sum to be delivered by the $i^{\text {th }}$ machine of $j^{\text {th }}$ items. $a_{i}$ and $b_{j}$ are the manufacture capacity and demand requirement of the $i^{\text {th }}$ machine and $\boldsymbol{j}^{\text {th }}$ manufacture respectively.

Step 4: $\quad$ a. If $a_{i}<b_{j}$, leave the $\boldsymbol{i}^{\text {th }}$ row and readjust $b_{j}$ as $b_{j}^{l}=b_{j}-a_{i}$.

b. If $a_{i}>b_{j}$, leave the $\boldsymbol{j}^{\text {th }}$ column and readjust $a_{i}$ as $a_{i}^{l}=a_{i}-b_{j}$.

c. If $a_{i}=b_{j}$, leave either $\boldsymbol{i}^{\text {th }}$ row or $\boldsymbol{j}^{\text {th }}$ column but not both.

Step 5: $\quad$ Revolve step 1 to 4 until the capacity limit and request necessity are fulfilled.

Step 6: $\quad$ Calculate $p=\sum_{i=1}^{m} \quad \sum_{j=1}^{n} p_{i j} x_{i j}$, p being the maximum benefit, and $p_{i j}$ is the benefit unit of $\boldsymbol{i}^{\text {th }}$ row and $\boldsymbol{j}^{\text {th }}$ column of the TT. 
Example 1: Four manufacture $\mathbf{P}_{\mathbf{1}}, \mathbf{P}_{\mathbf{2}}, \mathbf{P}_{\mathbf{3}}$, and $\mathbf{P}_{\mathbf{4}}$ are created by three machines, $\mathbf{M}_{1}, \mathbf{M}_{\mathbf{2}}$ and $\mathbf{M}_{3}$, and their benefit edge are given below in Table 1 . We are required to locate a reasonable arrangement of creation in machines.

This is done so that the retention and necessities are fulfilled and the benefit is maximized.

Table 1. Demand vs. Capacity of supply

\begin{tabular}{|l|c|c|c|c|c|}
\hline \multirow{2}{*}{ Machines } & \multicolumn{4}{|c|}{ Products } & Capacity of \\
\cline { 2 - 6 } & $\mathbf{P}_{1}$ & $\mathbf{P}_{2}$ & $\mathbf{P}_{\mathbf{3}}$ & $\mathbf{P}_{\mathbf{4}}$ & Supply \\
\hline$M_{1}$ & $\mathbf{2}$ & $\mathbf{5}$ & $\mathbf{4}$ & $\mathbf{7}$ & $\mathbf{4}$ \\
\hline $\mathbf{M}_{2}$ & $\mathbf{6}$ & $\mathbf{1}$ & $\mathbf{2}$ & $\mathbf{5}$ & $\mathbf{6}$ \\
\hline $\mathbf{M}_{3}$ & $\mathbf{4}$ & $\mathbf{5}$ & $\mathbf{2}$ & $\mathbf{4}$ & $\mathbf{8}$ \\
\hline Demand & 3 & 7 & 6 & 2 & $\mathbf{1 8}$ \\
\hline
\end{tabular}

The allocation is shaped by the distinction among the biggest unit benefit and the average value of total unit benefits.

Table 2. Row and column distribution indicator

\begin{tabular}{|c|c|c|c|c|c|c|c|c|c|c|c|}
\hline \multirow[t]{2}{*}{ Machines } & \multicolumn{4}{|c|}{ products } & \multirow{2}{*}{$\begin{array}{l}\text { Capacity } \\
\text { of } \\
\text { Supply }\end{array}$} & & & & & & \\
\hline & $P_{1}$ & $P_{2}$ & $P_{3}$ & $P_{4}$ & & \multicolumn{6}{|c|}{ Row distribution indicator } \\
\hline$M_{1}$ & 2 & 25 & 4 & $22_{7}$ & 4 & 3.08 & 1.08 & 1.08 & 1.08 & & \\
\hline$M_{2}$ & $33_{6}$ & 1 & $33_{2}$ & 5 & 6 & 2.08 & 2.08 & 1.92 & & & \\
\hline$M_{3}$ & 4 & $5_{5}$ & $3_{2}$ & 4 & 8 & 1.08 & 1.08 & 1.08 & 1.08 & 1.08 & 1.08 \\
\hline Demand & 3 & 7 & 6 & 2 & 18 & & & & & & \\
\hline \multirow{6}{*}{ 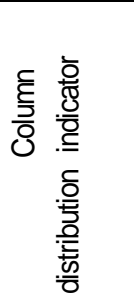 } & 2.08 & 1.08 & 0.08 & 3.08 & & & & & & & \\
\hline & 2.08 & 1.08 & 0.08 & & & & & & & & \\
\hline & & 1.08 & 0.08 & & & & & & & & \\
\hline & & 1.08 & 0.08 & & & & & & & & \\
\hline & & 1.08 & 1.92 & & & & & & & & \\
\hline & & 1.08 & & & & & & & & & \\
\hline
\end{tabular}

Therefore, the profit $\mathrm{P}=(2 * 5)+(2 * 7)+(3 * 6)+(3 * 2)+(5 * 5)+(3 * 2)=79$.

Example 2: Four manufacture $\mathbf{P}_{1}, \mathbf{P}_{2}, \mathbf{P}_{\mathbf{3}}$, and $\mathbf{P}_{\mathbf{4}}$ are created by three machines $\mathbf{M}_{1}, \mathbf{M}_{2}$, and $\mathbf{M}_{3}$ and their benefit edge are given below in Table 3. We are required to locate a reasonable arrangement of creation in machines. This is done so that the retention and necessities are fulfilled and the benefit is maximized. 
Table 3. Demand vs. Capacity of supply

\begin{tabular}{|c|c|c|c|c|c|}
\hline \multirow[t]{2}{*}{ Machines } & \multicolumn{4}{|c|}{ Products } & \multirow{2}{*}{$\begin{array}{l}\text { Capacity of } \\
\text { Supply }\end{array}$} \\
\hline & $\mathbf{P}_{1}$ & $\mathbf{P}_{2}$ & $\mathbf{P}_{3}$ & $\mathbf{P}_{4}$ & \\
\hline $\mathbf{M}_{1}$ & 4 & 2 & 5 & 3 & 6 \\
\hline $\mathbf{M}_{2}$ & 5 & 4 & 3 & 2 & 13 \\
\hline $\mathbf{M}_{3}$ & 1 & 4 & 6 & 5 & 9 \\
\hline Demand & 7 & 8 & 5 & 8 & 28 \\
\hline
\end{tabular}

The allocation is shaped by the distinction among the biggest unit benefit and the average value of total unit benefits.

Table 4. Row and column distribution indicator

\begin{tabular}{|c|c|c|c|c|c|c|c|c|c|c|c|}
\hline \multirow{3}{*}{$\begin{array}{c}\text { Machines } \\
\\
M_{1}\end{array}$} & \multicolumn{4}{|c|}{ products } & \multirow{2}{*}{$\begin{array}{l}\text { Capacity } \\
\text { of } \\
\text { Supply }\end{array}$} & & & & & & \\
\hline & $P_{1}$ & $P_{2}$ & $P_{3}$ & $P_{4}$ & & \multicolumn{6}{|c|}{ Row distribution indicator } \\
\hline & 4 & $2_{2}$ & 5 & $44_{3}$ & 6 & 1.33 & .33 & .67 & .67 & 1.67 & \\
\hline$M_{2}$ & $7_{5}$ & $6_{4}$ & 3 & 2 & 13 & 1.33 & 1.33 & .33 & .33 & .33 & .33 \\
\hline$M_{3}$ & 1 & 4 & $5_{6}$ & $4_{5}$ & 9 & 2.33 & 1.33 & 1.33 & & & \\
\hline Demand & 7 & 8 & 5 & 8 & 18 & & & & & & \\
\hline \multirow{6}{*}{ 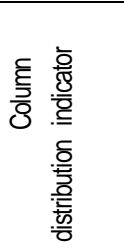 } & 1.33 & .33 & 2.33 & 1.33 & & & & & & & \\
\hline & 1.33 & .33 & & 1.33 & & & & & & & \\
\hline & & .33 & & 1.33 & & & & & & & \\
\hline & & .33 & & .67 & & & & & & & \\
\hline & & .33 & & & & & & & & & \\
\hline & & .33 & & & & & & & & & \\
\hline
\end{tabular}

Therefore, the profit is $\mathrm{P}=(2 * 2)+(4 * 3)+(7 * 5)+(6 * 4)+(5 * 6)+(4 * 5)=125$.

\section{Comparison of Profit Obtained by New Methods}

Consequently, we represent the present method (North West Corner Rule), Column Minima Method, Matrix Minima Method, and Vogel's Approximation Method. Here, the present method gives the better result than the other methods. In example 1, the result of the present method shows a significant difference than the other four methods. In example 2, the present method's result is nearest to North West Corner Rule (NWCR). Furthermore, the result of Column Minima Method (CMM) is closest to Matrix Minima Method (MMM) and Vogel's Approximation Method (VAM). 
Table 5. Comparison of profit obtained by new methods

\begin{tabular}{|l|c|c|}
\hline \multirow{2}{*}{ Methods } & \multicolumn{2}{|c|}{ Benefits } \\
\cline { 2 - 3 } & Example -1 & Example - 2 \\
\hline Presented Method & $\mathbf{7 9}$ & $\mathbf{1 2 5}$ \\
\hline NWCR & $\mathbf{3 7}$ & $\mathbf{1 1 9}$ \\
\hline Column minima Method & $\mathbf{3 7}$ & $\mathbf{6 4}$ \\
\hline Matrix minima Method & $\mathbf{3 7}$ & $\mathbf{5 8}$ \\
\hline VAM & $\mathbf{3 7}$ & $\mathbf{5 8}$ \\
\hline
\end{tabular}

Subsequently, we may demonstrate the benefits acquired in various strategies by the Bar chart as shown in Figure 1 below:

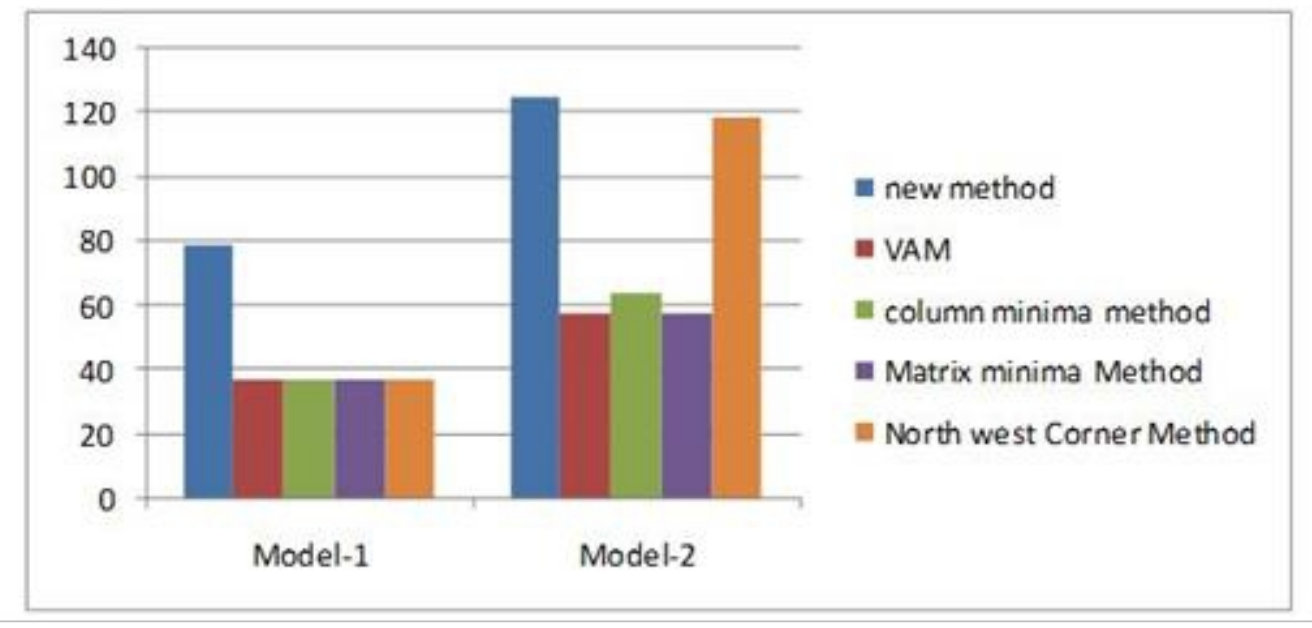

Figure 1. Comparision of profit maximization for Table 5

\section{Conclusion}

In conclusion, the exhibited technique encourages the director to organize the creation plan which maximizes the benefit of the manufacturing company. In the first example, we see that the benefit given by our technique is best than the other methods. In the second example, we see that the benefit is nearer to the benefit of NWCM than the other methods. So the technique improved here can be utilized for understanding any sort of benefit maximization. Hence, the new method helps to proffer a solution.

\section{References:}

1. Adlakha, V. \& Kowalski, K. (2003). A Simple heuristic for solving Small Fixed Charge Transportation Problems, Omega,Vol.31, No.3, pp.205-211.

2. Ahuja, K.K. (2007). Production Management, CBS Publishers and Distributors, New Delhi, India. 
3. Anderson, Sweeney and Williams. An Introduction to management Science quantitative Approaches to decision making.Chp-7, pp 296315.

4. Balakrishnan, N. (1990). Modified Vogel's Approximation Method for Unbalance Transportation problem, Applied Mathematics Letters, Vol.3, No.2, pp.9-11.

5. Dr. Ganesh Chandra Ray. Operation Research, Transportation and Assignment Problem, pp 56-80.

6. Gupta, P.K. \& Hira, D.S. (2009). Operations Research, S. Chand and Company Ltd. New Delhi.

7. Kapoor, V.K. (2002). Operations Research, Sultan Chand and Sons, New Delhi.

8. Kasana, H.S. \& Kumar, k.D. (2004). Introductory Operations Research: Theory and Applications, springer international Publications,pp.509-511.

9. Korukoglu, S \& Balli, S. (2011). An Improved Vogel's Approximation Method for the Transportation Problem, Association for Scientific Research, Mathematical and Computational Application Vol.16 No.2, 370-381.

10. Pandian, P. \& Nataraj, G. (2010). A New Approach for solving Transportation Problems with Mixed constraints, Journal of physical Sciences, Vol.14, pp.53-61.

11. Ravindran, A., Don, T., Phillips James, J. Solberg. Operation Research: Principles and Practice, John Wiley and sons, New York.

12. Swarup, K., Gupta, P.K. \& Man, M. Operation Research, Fourteenth Edition, S. Chand and Sons, New Delhi.

13. Taha, H.A. Operation Research, An Introduction, Sixth Edition, Prentice -Hall of India Private Ltd.

14. www.easycalculation.com/operation-research. 